\title{
Llengua i literatura segons Dante Elena Pistolesi
}

\section{Dante, pare de la llengua italiana}

La idea de Dante Alighieri com a pare de la llengua italiana només té cent anys perquè no es va formular fins després de la creació del nou estat italià a la segona meitat del segle XIX. Al 1865, quatre anys després de la consecució de la unitat política d'Itàlia, es va celebrar a Florència un colloqui dedicat al centenari del naixement de Dante (1265-1321), del qual van sortir dos volums mida foli, de mil pàgines en total, amb el títol Dante e il suo secolo; van representar un esforç increïble per un país mancat d'infraestructures i tot just acabat de néixer (Dionisotti 1967: 279-87). Aquest va ser el primer homenatge que la nació sencera, des de la capital provisional d'aquella època, va tributar al «profeta del Risorgimento» $\mathrm{i}$ al «creador de l'ànima nacional». El 1888 va nèixer, sempre a Florència, per iniciativa dels intellectuals més prestigiosos d'aquella època, la Società Dantesca Italiana, que havia de tenir cura de les edicions crítiques de les obres del pare de la pàtria i d'un Bullettino d'estudis, fundat el 1890. Abans d'aquest esclat nacional la fortuna desigual de Dante la podríem resumir amb la paraula desconfiança: tradicionalment el seu pensament, la seva imatge, fins i tot la seva llengua i la seva literatura havien generat desconfiança.

Sovint es repeteix que la gramàtica de la llengua italiana es basa en les «Tre Corone», és a dir Dante, Petrarca i Boccaccio. La primera gramàtica impresa de l'italià va ser publicada al 1525 per un venecià, Pietro Bembo, que va indicar com a models la llengua de Petrarca, per a la poesia, i la de Boccaccio, per a la prosa (Marazzini 1998). Dante hi és present perquè no es podia amagar el seu paper, però la seva llengua era massa híbrida, massa experimental i massa lliure per a les necessitats de la norma emergent. En efecte, la Commedia és una peça única que no té models en la tradició i que, malgrat la seva fortuna universal, tampoc no ha tingut seguidors. Dante va escriure la Commedia, en «terzine», tercets encadenats narratius, que eren un metre del tot inusitat; tota l'obra arrela en una poètica que no té precedents i és escrita en una llengua i en un estil completament nous. És una obra plurilingüe, que conté paraules llatines, dialectals, provençals, neologismes, cites en llatí i provençal, però, en canvi, el teixit de referències de context és profundament florentí. També és, de fet, l'obra més florentina entre totes les que Dante va compondre.

Un segle després del colloqui de Florència, Bruno Migliorini, a la seva Storia della lingua italiana, dedicava un capítol sencer a Dante definint-lo com el «pare del nostre idioma nacional». Podríem dir que la Commedia, més que la resta de la producció en vers i en prosa de Dante, va obrir al vulgar italià una gamma de tonalitats i d'arguments (filosòfics, teològics, polítics, científics, polèmics $i$ fins i tot profètics) que aquest mai no havia conegut, i això en feia una llengua que podia competir amb el llatí per la seva maduresa. Avui tenim els mitjans per comprovar si aquesta apreciació s'ajusta a la veritat, tenint en compte que la Commedia és una obra literària que conté uns 7.000 vocables.

Tornem enrere per veure quina era la situació de la llengua vulgar a Itàlia abans de Dante. Trobarem un panorama del tot diferent d'allò que passava a Catalunya a l'època de Ramon Llull. 


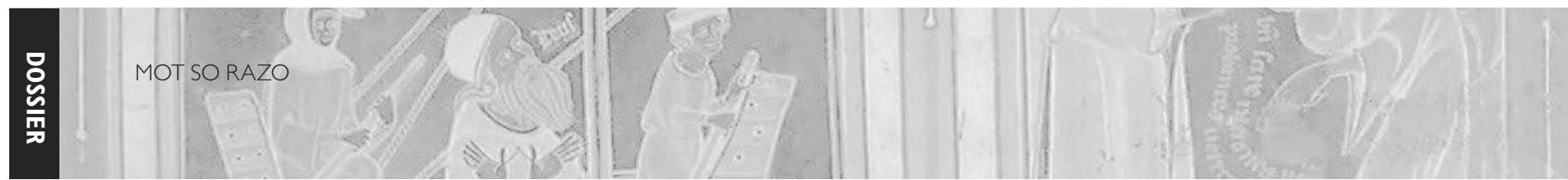

El vocabulari fonamental de l'italià, és a dir el nucli funcional del seu lèxic, conté 2.000 paraules: aquestes 2.000 paraules constitueixen aproximadament el $93 \%$ del repertori lèxic que trobem a tota mena de textos, tant escrits com orals. Aquest nucli de 2.000 paraules és també el més antic: quan Dante va començar a escriure el seu poema, al voltant del 1300, el vocabulari fonamental ja estava constituït en un 60\%; la Commedia se n'apropia, l'integra, i ens el transmet amb un segell propi. Al final del segle XIV el vocabulari fonamental estava configurat en un $90 \%$ i la contribució de Dante va ser, sense dubte, cabdal (De Mauro 2000: 1183).

\section{Dante, crític de la literatura}

Dante té un paper destacat a les històries de la literatura no només per la seva obra incomparable, sinó també perquè va reflexionar sobre la literatura de la seva època. Això per a un home dels seus temps volia dir repensar la poesia lírica; va triar-ne els models i va construir un marc de referència dins del qual la seva actuació va acabar essent en part una continuitat i en part un trencament. Quan selecciona els seus precursors ell mateix esdevé un crític de la literatura i tant a la Vita Nova com al De vulgari eloquentia la història de la lírica es dibuixa en funció de la seva pròpia tasca. Els manuals de literatura dels nostres dies encara reporten, amb poques variacions, els judicis literaris que va proposar Dante.

La llengua vulgar de Sicília es va adoptar per primera vegada per a les composicions líriques a la cort de Frederic II Staufen, coneguda com la Magna Cúria. Els poetes sicilians tenien com a model la poesia trobadoresca, de la qual conservaren els metres, les convencions de contingut i fins i tot certes formes lèxiques («amanza», «allegranza», «leanza», «coragio», etc.). L'experiència de l'anomenada escola siciliana es va acabar el 1250 amb la mort del rei, però el corpus dels seus textos va ser copiat $\mathrm{i}$ imitat pels poetes dits sículo-toscans. Dante va escriure al De vulgari que els poetes de la Magna Cúria havien abandonat el seu vulgar per escriure en una llengua illustre supramunicipal. Deia això perquè els llegia a través de les còpies que s'havien fet a la Toscana, en les quals s'havia adaptat la llengua. De tota manera, si deixem de banda la poesia religiosa del centre i del nord d'Itàlia i la poesia didàctica que podríem qualificar de llombarda, la història de la lírica italiana en vulgar és la història de la tradició de l'escola siciliana, que, passant per la Toscana (començant per Pisa, Lucca i Arezzo), arriba fins als poetes estilnovistes, és a dir fins a Dante, que matisa aquesta línia de difusió.

En contrast amb la producció lírica, que al segle XIII ja té un nivell remarcable i una tradició consolidada, la prosa en vulgar no tindrà models fins al segle XIV, és a dir fins a Boccaccio. El domini del llatí en tots els camps del coneixement era absolut i, pel que fa a la prosa narrativa, els escriptors italians feien servir més aviat el francès, com va passar en el cas del Milione de Marco Polo i del Tresor de Brunetto Latini, obres que només van ser traduïdes al toscà algun temps després de la seva composició. Al segle XIII, la prosa en vulgar italià no contraposava cap model unitari als del llatí i el francès, perquè a diferència d'allò que havia passat amb la poesia, cap vulgar italià no es va imposar sobre els altres. Aquest és el

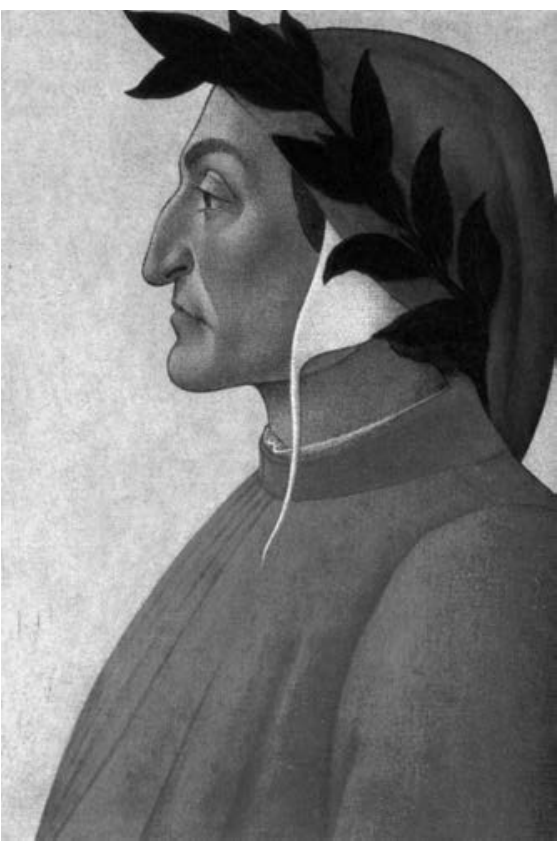

Dante Alighieri (detall) representat en el famós retrat atribuït a Sandro Boticcelli (Colònia, Col-lecció M. Bodmer). 


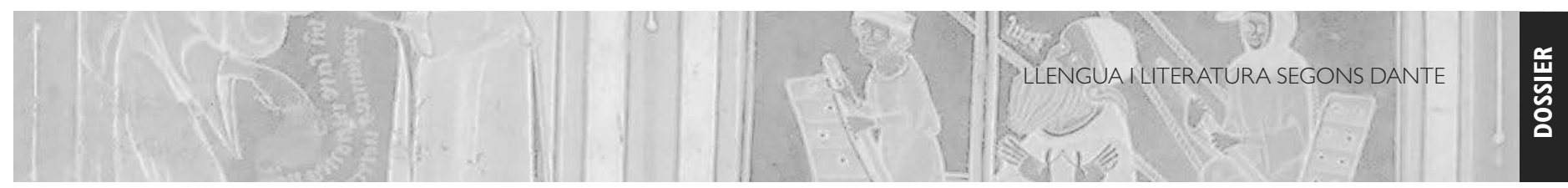

marc on cal situar la producció i la reflexió sobre la llengua vulgar de Dante, que són dues facetes que sempre caminen de bracet.

Si per a Llull la literatura no és mai una finalitat en ella mateixa, sinó un mitjà per transmetre el missatge de l'Art, per a Dante és al contrari: literatura i vida, literatura i política, literatura i missió són una mateixa cosa. Ho comprovarem amb la figura del personatge polifacètic Dante que diu «jo» en totes les seves obres.

\section{De la "Vita Nova» a la "Commedia»}

La llengua i la literatura, la teoria poètica i la reflexió sobre la llengua vulgar són indestriables en l'obra de Dante. En realitat podríem dir que quan parla de la llengua vulgar Dante parla de lingüística perquè situa les seves reflexions en el marc del panorama lingüistic italià. El fet que Dante escollís el vulgar matern per a les rimes era del tot normal a la seva època; ja era menys normal que defensés aquesta opció amb prou arguments i al llarg de tota la vida i que acabés escrivint en llengua vulgar el «poema sacro | al quale ha posto mano e cielo e terra» ('poema sacre, on han posat la mà el cel i la terra') (Par XXV, 1-2).

Què significa per a ell ser poeta? La Vita Nova és una obra en prosa $i$ en vers - un prosímetre- que Dante va compondre entre 1294 i 1295, abans que l'expulsessin de Florència el 1302 per raons polítiques. En aquella temporada l'horitzó de Dante havia estat el cercle dels poetes estilnovistes, un petit grup d'escriptors que estava protagonitzant una revolució literària a través de la lírica, dirigida a la burgesia de la seva ciutat. Segons el programa estilnovista, inspirat per la composició «Al cor gentil rempaira sempre amore» ('L'amor es refugia sempre en el cor gentil'), de Guido Guinizzelli, la noblesa d'ànim, sense cap referència a la sang i al llinatge, és el fonament de la virtut i només els «cors gentills», és a dir nobles en aquest nou sentit, poden conèixer què és l'amor. La Vita Nova representa alhora la consolidació i la superació d'aquest model.

1. Per a la traducció de la Comèdia al català es fa referència a la versió de Mira, vegeu Alighieri (2000).

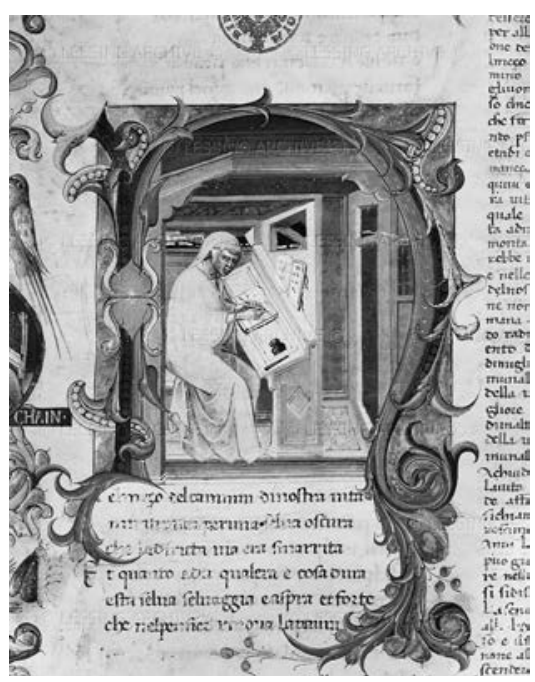

Inicial de finals del segle XIv que representa Dante escrivint la Commedia (París, Bibliothèque Nationale de France, ms. it. 74).

Al paràgraf 16 de la Vita Nova Dante dibuixa un perfil de la història de la lírica en vulgar i acaba dient que els «rimatori», els versaires, en vulgar es podien comparar amb el poetes «litterati», llatins i grecs, els únics que fins a aquell moment havien tingut dret al títol de «poetae». ${ }^{2}$ Per primera vegada es reconeix el mateix valor a la poesia en vulgar i a la poesia llatina: «ché dire per rima in volgare tanto è quanto dire per versi in latino, secondo alcuna proporzione» ('perquè fer poesia en llengua vulgar equival a fer poesia en llatí, segons els relatius sistemes mètrics'). La poesia de la qual està parlant Dante és només la poesia d'amor, concretament la seva i la dels seus amics, especialment la de Guido Cavalcanti. Dante ens explica al mateix paràgraf 16 que la poesia d'amor en vulgar tenia només cent cinquanta anys i que havia nascut per dialogar amb les dones perquè ignoraven el llatí. Segons aquesta visió, la poesia d'amor era l'única legítima, la sola que podia transformar els «rimatori», els versaires, en autèntics poetes: la Vita Nova no admet cap composició que no sigui de tema amorós. És exactament el contrari del que diu Llull al capítol 118 del Llibre de contemplació, on «desacredita totalment la poesia dels trobadors i expressa el propòsit d'evitar qualsevol contaminació amb la tradició lírica», com expliquen Badia, Santanach i

2. Sobre el concepte de poeta en les obres de Dante, vegeu Tavoni (1996). 
Soler en la seva collaboració del present dossier.

Alguns anys després, al De vulgari, els temes dignes de ser tractats en vulgar esdevenen tres (salut, amor i virtut), però en aquest context només els poetes tràgics poden ser anomenats «poetae», és a dir Cino da Pistoia, Guido Cavalcanti i Guido Guinizzelli i a més, evidentement, el mateix Dante. Al Convivio, que va començar a escriure veritablement al 1305 en parallel amb el De vulgari, l'autor que a la Vita Nova només reconeixia l'amor com a matèria digna de ser tractada en vers, ara ha d'explicar la seva conversió a la poesia doctrinal. L'obra comença amb una cita d'Aristòtil: «Sì come dice lo Filosofo nel principio de la Prima Filosofia [la Metafísica], tutti li uomini naturalmente desiderano di sapere»»3.3 ('Així com diu Aristòtil al començament de la Metafísica, tothom desitja conèixer de forma natural'). Tot seguit Dante declara els seus deutes envers les autoritats de Boeci i sant Agustí. En aquest cas la finalitat del tractat, que, com la Vita Nova, és un prosímetre, no és tant justificar la poesia en vulgar de qualsevol tipus, sinó fundar una prosa doctrinal en vulgar que, com hem vist, no tenia cap tradició de referència en la seva llengua vernacla. El Convivio cita només poetes llatins; l'únic poeta vulgar que hi troba lloc és el propi Dante, perquè les cançons objecte del comentari filosòfic són seves: al Convivio no queda espai per a cap altre poeta vulgar que no sigui ell.

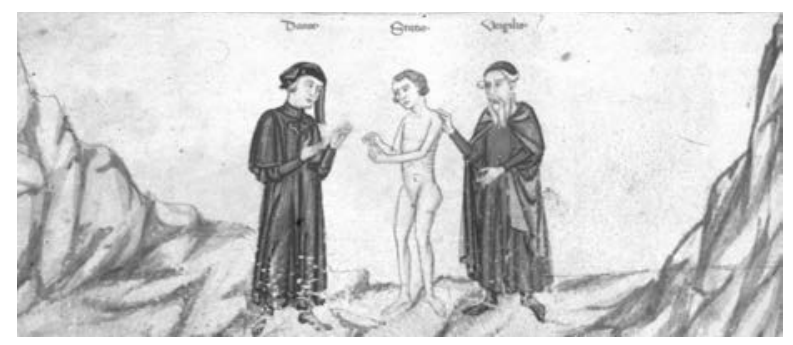

Dante, Virgili i Estaci a l'Infern en una miniatura de la Commedia (Oxford, Bodleian Library, ms. Holkham misc. 48).

La continuïtat entre la Vita Nova i el Convivio està justificada en un passatge molt conegut, en què Dante aplica una lectura alllegòrica als seus versos. De seguida aclareix que aquesta lectura

3. Sobre aquest tòpic en les obres de filosofia per als laics, amb la referència a la Metafísica d'Aristòtil, vegeu Imbach (2003: 37, 63, 64 i 130-49). no té res a veure amb la dels teòlegs, sinó que cal relacionar-la amb la del poetes. Els poetes als quals fa referència son els llatins, com Ovidi, els quals expressen la veritat «ascosa sotto bella menzogna» ('amagada sota una bella mentida'): aplicant a la seva poesia diferents nivells de lectura, Dante reprèn la poesia d'amor de la Vita Nova, que ara, després d'aquesta investidura filosòfica, es pot interpretar tant en sentit literal com en sentit allegòric. Afirmant que la seva poesia d'amor en vulgar es pot llegir segons els principis de l'allegoria, Dante intensifica la densitat conceptual de la seva obra passada i li afegeix noves significacions. Al Convivio, però, Dante es queda sol: només ell podia fundar una prosa doctrinal digna d'igualar el llatí universitari. Al Convivio la seva legitimitat com a escriptor de prosa «illustre» passa a través de la primacia adquirida amb la poesia.

Dante comparteix amb Llull la pràctica de l'autoreferència i de l'autocitació. Per exemple, a partir del capítol VIII del llibre segon del De vulgari trobem citades només les seves pròpies composicions com a models d'estil. Com Llull, Dante també practica la remissió a poesies i temes elaborats per ell mateix en moments diferents. Ja hem vist la finalitat que té l'autoexegesi al Convivio: crear una continuïtat intellectual entre les seves experiències d'escriptura passades i donar vida a una imatge complexa en la qual —com veurem - la ficció i la biografia són indestriables

A la Commedia Dante afirma que ell és l'únic «poeta» que escriu en un idioma modern. Com havia passat al Convivio, al poema la seva producció anterior tampoc no queda oblidada. Per exemple, als cants XXIV i XXVI del Purgatori parla de l'experiència estilnovista amb Guido Guinizelli i Bonagiunta da Lucca, i ho fa, com sempre, llegint la seva història i la dels seus companys en funció del present, la Commedia, o sigui de la composició d'una obra que no té comparació amb cap altra i que els seus amics ni tan sols podien concebre. El lector ja s'ha adonat d'aquesta distància: només Dante podia atrevir-se a edificar l'espai literari i històric de la Commedia. La seva producció sempre havia estat una novetat al costat dels gèneres tradicionals, i Dante sempre havia reivindicat la 


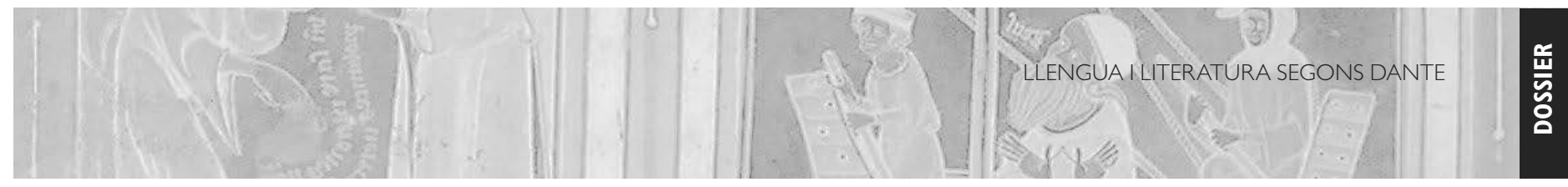

novetat absoluta de la seva obra. Més enllà del tòpic de la novetat absoluta — que Llull comparteix-, les seves reivindicacions queden confirmades com a mínim en allò que hem dit sobre la prosa doctrinal a propòsit del Convivio. Amb la Commedia el trencament amb el seu temps fa encara un pas més.

\section{El gènere de la "Commedia»}

Sobre el títol de l'obra — en realitat la discussió és sobre el gènere - s'han vessat rius de tinta. El motiu és que en aquest cas Dante no ens dóna cap pista sobre les seves intencions, com havia fet fins al Convivio: la seva actitud sembla fins i tot reticent. Els testimonis més antics de l'obra enregistren el títol de Commedia, però al text no hi ha cap indici que ens el confirmi. Dues referències sempre esmentades són, d'una banda, l'Epistola a Cangrande, on es parla de la «Comedia» (però aquesta epístola és d'autoria dubtosa); de l'altra, l'incís de la Monarchia, on es llegeix «sicut in Paradiso Comedie iam dixi» (I.xii.6, 'com ja vaig dir al Paradís de la Comèdia'), que podria ser una interpolació afegida posteriorment. La paraula «comedia» es troba dues vegades al poema: al cant XVI de l'Infern (vv. 127-28), «e per le note | di questa comedia» ('pels versos d'aquesta comèdia') i al principi del cant XXI (vv. 1-2): «Così di ponte in ponte, altro parlando | che la mia comedia cantar non cura» ('Així anàvem de pont en pont, parlant de coses que no vol tractar la meva comèdia'). No tenim cap altre indici que ens pugui indicar com qualificava Dante la seva obra. «Comedia» s'oposa aquí a «tragedìa», etiqueta que qualifica l'Eneida de Virgili. Dins del sistema medieval dels gèneres, comèdia indica una narració que comença amb una situació dolenta i s'acaba de manera feliç.

Al Paradís Dante defineix la seva obra dues vegades com a «poema»: «sacrato poema» (XXIII, 62) i «poema sacro» $(X X V, 1)$. El terme poema fa referència a la literatura èpica, la qual pertany a l'estil tràgic. Segons les categories del De vulgari, on Dante havia adoptat el sistema dels gèneres medievals confirmant la línia de les po- etriae medievals, comèdia i tragèdia resulten incompatibles. Les definicions que en donava no contenien cap novetat, però el problema és que, segons aquestes definicions, comèdia i tragèdia no podrien conviure. ${ }^{4}$

Qualsevol lector pot comprovar sense esforç, en la matèria i en la llengua de la Commedia, la mescla dels dos estils medievals, el baix de la comèdia i l'elevat de la tragèdia. Aquesta contigüitat és una revolució sense precedents perquè a la Commedia aquests conceptes de baix i d'elevat adquireixen un valor diferent. Durant el seu viatge ultraterrenal Dante es troba amb molts collegues: Arnaut Daniel, Folquet de Marselha, Giacomo da Lentini, Guido Cavalcanti, etc. Mai no els anomena amb la paraula «poeta», paraula que reserva només als poetes antics: Virgili, Homer, Horaci, Ovidi, Lucà i Estaci. Així, a la Commedia no hi ha cap poeta romànic a qui pugui atribuir-se el títol de poeta: ningú, excepte Dante, evidentement. A la Commedia Dante és queda sol, sense cap interlocutor contemporani. Què havia passat d'ençà de l'època de la Vita Nova, quan el nostre autor formava part d'un grup de poetes vernacles? Quan Dante escriu (Inf IV, 102) que va ser «sesto tra cotanto senno» ('sisè entre aquells savis'), els seus companys són Homer, Horaci, Virgili, Ovidi i Lucà. Des del principi de la Commedia, Dante colloca la seva obra en una línia de continuïtat amb la tradició antiga, sobretot amb el cànon que posava de costat la poesia èpica i la poesia satírica de Juvenal, Persi i Horaci perquè la sàtira moral feia part del gènere còmic. Segons la interpretació que dóna Marco Santagata (2011: LXXVI-LXXXIV), la paraula «comèdia» fa referència aquí a la sàtira de tipus moral: Dante reivindicava així el paper de poeta militant que critica i jutja la societat i el de profeta que la condemna des de la seva capacitat de visió. El mot comèdia no s'hauria d'interpretar, doncs, en referència a un gènere codificat, sinó com un espai literari en què conviuen els poetes tràgics i els poetes

4. Un altre model del seu poema és la Bíblia, que no pertany a cap gènere, perquè és un unicum, una obra única $\mathrm{i}$ irrepetible, on es fonen els temes i les tradicions $\mathrm{i}$ on es mesclen una gran varietat de nivells estilístics. 
satírics. La paraula «poema» que Dante empra al final de l'obra era la més apropiada per descriure aquest nou espai. Per això Dante va deixar de banda el terme «comedia» després de sortir de l'Infern, per passar a qualificar la seva obra de «poema».

\section{La teoria de la llengua vulgar}

A través de la paraula «poeta» hem vist quin lligam hi ha entre la poesia en vulgar i la poesia en llatí. El fet que Dante a la Commedia es reservi el títol de poeta representa el triomf de l'idioma vernacle. Dante va ser un teòric de la literatura i de la llengua, o més ben dit, un teòric de la literatura en vulgar. És cert que va escriure algunes obres en llatí, com la Monarchia, les Egloge i les Epistole, i fins i tot hi va escriure el tractat De vulgari eloquentia, dedicat a la llengua vernacla. No és una contradicció: si volia promoure la llengua vulgar en uns ambients que feien servir el llatí, havia d'emprar aquesta llengua. A més, l'associació entre llatí i vernacle no era inusual perquè els tractats sobre poesia, les poetriae, estaven escrits en llatí, com és el cas de la Summa artis rithimici vulgaris dictaminis d'Antonio da Tempo (1332), que tracta de mètrica romànica.

D'acord amb la seva manera de fer, que ja coneixem, Dante, a través d'anuncis i d'esments puntuals, posa en relació directa les seves obres amb referències $i$ interpretacions que se sobreposen a les precedents i que les remodelen. Aquest és el cas del Convivio i del De vulgari, les dues obres seves que justifiquen teòricament l'ús de la llengua vulgar. El Convivio neix d'un acte d'ambició generosa: compartir amb un públic laic els coneixements reservats als ambients universitaris i clericals. La llengua vulgar és l'instrument necessari per aconseguir aquesta finalitat i una part imprescindible d'un programa cultural alternatiu. AI Convivio Dante proposa un comentari en llengua vulgar de les seves cançons, on explica la seva dedicació a la filosofia després de la mort de Beatrice, la protagonista de la Vita Nova. Com i quan s'havia acostat a la filosofia? No sabem res dels seus estudis ni de la seva formació cultural — passa el mateix amb Llull, que no cita mai les seves fonts: segons el testimoni del Convivio (II.XII), després de la mort de Beatrice, Dante hauria llegit el De consolatione philosophiae de Boeci i el Laelius de amicitia de Ciceró. Hauria estudiat filosofia durant trenta mesos, tot freqüentant les «scuole dei religiosi» i les «disputazioni dei filosofanti» a Florència probablement als ambients dominicans de Santa Maria Novella, als franciscans de Santa Croce i als agustinians de Santo Spirito. No sabem si va tenir relacions amb els ambients universitaris de Bolonya i de París: segur que va ser a Bolonya abans del 1287 i probablement hi era l'any 1305, mentre que del viatje a París en quedaria només la referència al «Vico degli Strami» on Siger de Brabant «silogizzò invidiosi veri» (Par X, 136-38), és a dir que sillogitzà veritats amb gran risc.

Cal destacar que amb el Convivio i el De vulgari Dante canvia de públic: si a la Vita Nova aquest era format per un grup escollit de burgesos de la seva ciutat dotats de «cor gentil», en aquestes dues obres, en polèmica contra els intellectuals ciutadans que l'havien condemnat a l'exili, es dirigeix als nobles que viuen fora de les ciutats, als senyors feudals, a les grans famílies de la Itàlia del centre-nord que li donen hospitalitat. Com li diu Beatrice al cant XVII del Paradís (Vv. 55-60):

Tu lascerai ogne cosa diletta più caramente; e questo è quello strale che l'arco de lo essilio pria saetta.

Tu proverai si come sa di sale lo pane altrui, e come è duro calle lo scendere e 'I salir per l'altrui scale.

[Tu deixaràs tot allò que t'estimes amb més amor, perquè aquesta és la fletxa que dispara primer l'arc de l'exili. Tu tastaràs quin gust que fa de sal el pa d'altri, i quin camí tan dur és baixar i pujar escales d'altri.]

Tot el primer llibre del Convivio està dedicat a la tria de la llengua vulgar: com que el llatí té més noblesa, virtut i bellesa (salus, venus, virtus) que el vulgar, no hauria pogut ser fidel a la poesia en vulgar, la qual per la seva naturalesa és intraduïble. El llatí és més noble perquè «perpetuo e non cor- 


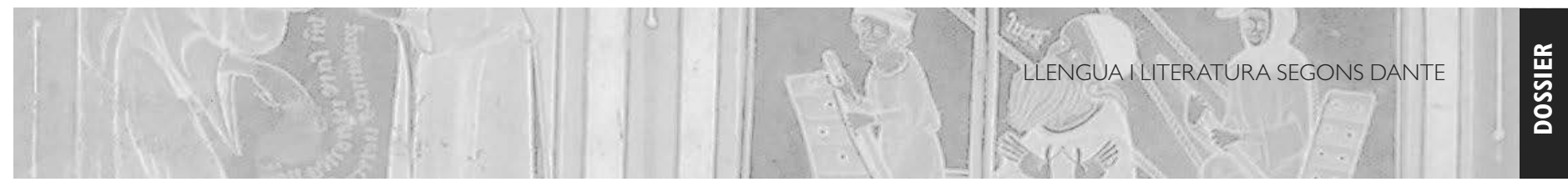

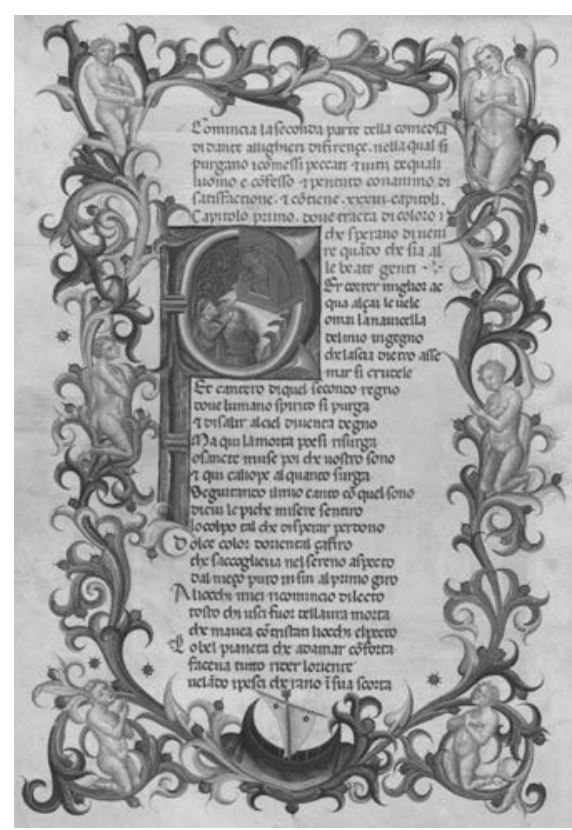

Manuscrit de la Commedia (Madrid, Biblioteca Nacional de España).

ruttibile e lo volgare è non stabile e corruttibile» ('perpetu i no corruptible mentres que la llengua vulgar és inestable i corruptible') (I, 8-9). La llengua vulgar canvia en el temps, mentre que el llatí mai no canvia, per això encara avui podem llegir les obres del poetes i les comèdies en aquesta darrera llengua. D'aquest tema, diu Dante, en parlaré «in uno libello ch'io intendo di fare, Dio concedente, di Volgare Eloquenza» ('en un llibre petit que jo vull escriure, si Déu m'ho concedeix, sobre l'Eloqüència en Llengua Vulgar'). Al De vulgari escriurà, per contra, que el vulgar és superior perquè és una llengua natural, mentre que el llatí (dit «grammatica») és una creació artificial. Deixem de banda les contradiccions que la crítica ha vist entre les dues obres i fixem-nos en la idea més innovadora que les agermana: la idea de la historicitat de les llengües, el fet que canvien constantment. A partir de l'episodi babèlic que havia condemnat la humanitat al plurilingüisme, Dante al De vulgari dibuixa la geografia lingüística d'Europa i de la península italiana i la considera, tot i la seva fragmentació en parles municipals, un espai únic, que anava des del vulgar de Sicília fins al friülà. Sobre aquesta àrea plurilingüe, composta com a mínim de catorze vulgars, Dante aposta pel futur de la literatura i pel futur polític d'un territo- ri que, parlant de la seva peregrinació d'exiliat, al Convivio (I.III.4) defineix d'aquesta manera: «per le parti quasi tutte a le quali questa lingua si stende» ('més o menys a tots els llocs on aquesta llegua s'estén'). Al De vulgari Dante dibuixa un mapa de les diverses varietats indicant quins poetes s'havien allunyat del vulgar municipal per apropar-se al vulgar «illustre, curiale, aulico e cardinale». Els temes dignes d'aquesta llengua illustre ara són, com hem vist, la terna salus, venus, virtus i la forma mètrica més noble és la cançó. A propòsit de la tria entre vulgar i llatí, la distància amb Ramon Llull és enorme. El mallorquí fa servir més d'una llengua i fins i tot practica l'autotraducció, sense justificar mai des del punt de vista teòric les seves opcions lingüístiques (Pistolesi 2009).

Al capítol IX del llibre I (paràgraf 5) del Convivio, escrit després de l'exili, Dante afirma que l'ús del vulgar serà útil a «principi, baroni, cavalieri, e molt'altra nobile gente, non solamente maschi ma femmine, che sono molti e molte in questa lingua, volgari e non literati» ('prínceps, barons, cavallers, i moltes altres persones nobles, no solament homes sinó dones, els quals són nombrosos en aquesta llengua, sense cap coneixement de llatí'). La Commedia reinventa també la relació amb el públic: per primera vegada una obra literària no s'adreça a un grup selecte de poetes, nobles, laics o a les dones, sinó a tothom (Santagata 2011: CXVII). La ideologia que Dante expressa a la Monarchia i al Paradís quan es troba el seu avantpassat Cacciaguida és una ideologia imperial, una visió del món que exalta l'època anterior a les guerres entre faccions ciutadanes, quan la noblesa moral corresponia a la noblesa de sang. Aquesta solució és coherent amb el missatge del Paradís; Dante hi havia madurat la consciència de la seva missió que, en un primer moment, immediatament després de l'exili, es limitava a un horitzó exclusivament italià, com es desprèn de l'espai descrit al De vulgari.

\section{La coherència del personatge Dante}

Hi ha alguns llocs concrets en la producció de Dante que semblen prou incoherents, com, per 


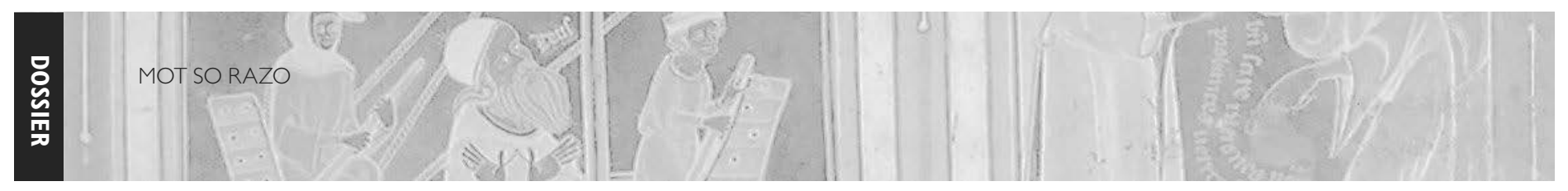

exemple, el de la ideologia política que acabem d'esmentar. Aquests aparents contrasentits s'expliquen per les contingències de la seva reflexió sobre la llengua i la literatura, lligada sempre a la seva experiència personal: l'autobiografia literària - que Dante reinterpreta a cada pas segons les exigències d'un pensament nou- i l'autobiografia històrica són quasi indestriables. Aquestes contingències, que acaben confluint en el marc de la Commedia, comporten uns canvis que poden semblar contradictoris si no els colloquem dins d'un marc d'experimentalisme constant relacionat amb una evolució intellectual que afecta tant el personatge que diu jo a cada obra com l'home Dante. Ho hem comprovat seguint els significats de la paraula poeta al llarg de la seva producció i les finalitats corresponents dins d'una teoria militant de la literatura. Dante sempre treballa per conquerir uns territoris inusitats per a l'expressió vernacla i per a la cultura que s'expressa en llengua vulgar. Al començament del procés aquest esforç cultural és compartit amb un grup de poetes i amics, mentre que al final Dante s'ha quedat tot sol — literalment sense ningú més - perquè, potser, en una època tan corrupta no podia haver-hi una colla de profetes, en calia un de sol.

Hem dit que hi ha alguns llocs concrets en la seva producció que resulten prou incoherents: la condemna de la literatura cortesana al cant $\mathrm{V}$ de l'Infern, amb la damnació de Paolo i Francesca; el sistema dels gèneres tal com es presenten al De vulgari al costat de la revolució de la Commedia; la tria d'un vocabulari illustre al tractat llatí que, però, no té cap correspondència en el «poema sacro»; la imatge de la Donna gentile, és a dir la filosofia, que domina entre la Vita nova i la Commedia en lloc de Beatrice, la protagonista de la primera obra i de la Commedia.

El De vulgari i el Convivio són dues obres inacabades perquè Dante va abandonar tots dos projectes abans de completar-los. D'altra banda, es tracta de dues obres que no van ser llegides abans del segle XIX: al XIV gairebé només les coneixia Boccaccio. Fins al segle XVIII la cronologia de les obres de Dante situava l'escriptura de la
Commedia immediatament després de la Vita Nova. Això comportava, entre altres coses, la continuïtat entre la figura de Beatrice del prosímetre juvenil i la Beatrice que viu entre els beats a la Commedia. Si no va acabar el De vulgari i el Convivio va ser perquè el projecte de la Commedia va molt més enllà dels programes respectius. Ja

La Commedia no pertany a la copiosa tradició medieval de les visions de l'altre món, però, de fet, tampoc no pertany a cap altre gènere perquè és un unicum. Hi ha dues referències al somni que semblen acreditar la idea que la Commedia és una experiència onírica. Al principi de l'obra ( Inf I, 10-2), quan el personatge ja s'ha endinsat en la selva, declara: «lo non so ben ridir com'i' v'intrai, | tant'era pien di sonno a quel punto | che la verace via abbandonaì) ('No sé explicar bé com hi vaig entrar: tan ple de son estava en aquell punt en què em vaig apartar del bon camí!'); al final, Sant Bernat (Par XXXII, 139-40) li diu: «Ma perché 'I tempo fugge che t'assonna, | qui farem punto...» ('Però, com que el temps fuig i et dóna son, posarem ací un punt'). Això s'ha interpretat com una referència a un somni real, és a dir una visio in somnis segons la convenció literària. Però hem de tenir en compte que més d'una vegada i de manera prou clara Dante afirma que parla en nom de Déu: per exemple, al Purgatori (XXXIII, 52-4) Beatrice li diu «Tu nota; e s̀ come da me son porte, | così queste parole segna a' vivi | del viver ch'è un correre a la morta» ('Pren nota; i tal com les explique jo escriu tu les paraules per als vius, | amb vida que és un córrer a la mort'). L'avantpassat Cacciaguida al Paradís (XVII, 127-29) li aconsella que: «Ma nondimen, rimossa ogne menzogna | tutta tua vision fa manifesta; | e lascia pur grattar dov'è la rogna» ('I tanmateix, sense dir cap mentida, has de contar allà tot el que has vist; i deixa que hom es rasque on té la ronya'). Sant Pere encara afegeix (Par XXVII, 64-6): «e tu, figliuol, che

per lo mortal pondo | ancor giù tornerai, apri la bocca, | e non asconder quel ch'io non ascondo» ('i tu, fill meu, que pel teu pes mortal has de tornar a baix, obre la boca i no amagues el que no amague jo). La missió de Dante és «notare» i «far manifesto» ('escriure i manifestar') el que veu a l'altre món. 


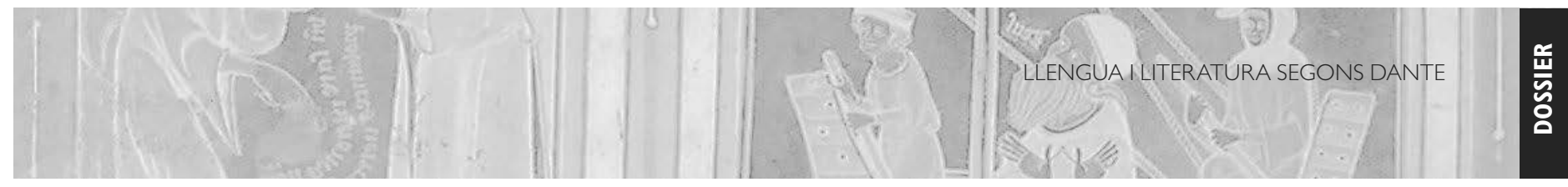

hem comentat que la Commedia supera la teoria dels gèneres i la de llengua del tractat llatí; de la mateixa manera, la tria de la terzina, el tercer encadenat narratiu, aplana la dicotomia entre prosa i vers i comporta el trencament d'un projecte tan ambiciós com la construcció d'una prosa doctrinal en vulgar defensat al Convivio. Això no significa que Dante mateix no deixi espai per a interpretacions diferents - fins i tot a propòsit de la seva producció- i que no canviï el seu horitzó; ho hem estat veient repetidament. Malgrat això, tenim una idea unitària de la seva obra, gràcies sobretot al personatge que porta el nom de Dante, que és el que li permet d'establir un pacte entre la ficció i la realitat. No distingir els dos plans i reconduir-los cap a una sola figura anomenada «Dante», real i fictícia alhora, és una part fonamental de la seva estratègia. De fet, el conjunt de l'obra dóna vida a un arxipersonatge únic i inimitable, un superpersonatge. 5 És una figura no gens exemplar, que dóna vida a una construcció intellectual que uneix les contingències de la biografia amb els valors universals, que connecta amb la utopia social i política. A la Commedia és molt evident que el personatge Dante porta diverses màscares, especialment quan es troba amb els amics i els enemics, és a dir amb persones que havia conegut i coneixia. El personatge que ens ha narrat la seva formació a la Vita Nova, que es dedica a la filosofia després de la mort de Beatrice, que escriu rimes per a més d'una dona i que clama contra el municipalisme al De vulgari, a la Commedia té una nova missió: la d'explicar als vius el món ultraterrenal. Aquesta darrera experiència, per molt que sigui atribuïda al personatge de ficció, no pot no afectar el narrador, l'home de carn i ossos.

La construcció dels rerefons d'aquest «jo» de Dante, particular i universal alhora, comporta dues conseqüències. La primera és l'autoexegesi, és a dir la lectura de la seva producció passada des d'un nou punt de vista, com hem vist amb el pas de la Vita Nova al Convivio. La segona conseqüència afecta el sentit global de la Commedia i la naturalesa de l'experiència dantesca: la Commedia

5. Sobre aquest concepte, vegeu Santagata (2011: CxIXCXXII). és una visió, una experiència mística real o una profecia?

Deixaré de banda aquest problema (que no té solució) dient que darrerament té força crèdit la imatge de Dante com a profeta (vegeu Santagata 2011: XXXIII-XXXVIII), per tal de subratllar, encara una vegada, el fet que la construcció d'una nova literatura i l'experiència única del seu promotor poden contenir allusions que escapen a la nostra comprensió, tal com ha passat en la recepció desigual de Dante al llarg dels segles.

Amb això podem tancar el nostre ràpid recorregut tornant al punt de partida, o sigui al Dante pare de la llengua italiana. Al segle XIX la filologia dantesca va aclarir molts aspectes de la seva producció i del seu pensament que fins llavors s'havien ignorat, com, per exemple, la cronologia relativa de les obres. Aquest reconeixement va ser tardà, però al moment de la unitat política d'Itàlia va ser sentit com a necessari. La nova Itàlia era un país que descobria les seves inesgotables diferències, tant de costums com de llengües (els dialetti), i que havia de superar aquell antic municipalisme en contra del qual Dante havia lluitat durant tota la seva vida d'exiliat polític. La seva actitud militant representava un estímul per a l'esperit italià emergent. El classicisme de Petrarca - que, tanmateix, havia aconseguit una fortuna imparable a tota Europa - no podia assumir de cap manera la funció ideològica que Itàlia necessitava en aquell moment. 


\section{Bibliografia citada}

Alighieri, Dante, 1995: / Convivio, ed. Franca Brambilla Ageno, Florència: Le Lettere.

Alighieri, Dante, 1994-97: Divina Commedia, ed. Anna Maria Chiavacci Leonardi, Milà: Mondadori, 3 vols.

Alighieri, Dante, 2000: Divina Comèdia, traducció, introduccions i notes de Joan F. Mira, Barcelona: Proa.

De Mauro, Tullio, 2000: «Postfazione» al Grande Dizionario italiano dell'uso, Torí: UTET, VI, 1163-8z.
DionisotTI, Carlo, 1967: «Varia fortuna di Dante», Carlo Dionisotti, Geografia e storia della letteratura italiana, Torí: Einaudi, 255-303.

IMBACH, Ruedi, 2003: Dante, la filosofia e i laici, Gènova-Milà: Marietti, 1820. [Edició original: Dante, la philosophie et les laïcs, Fribourg: Editions Universitaires, 1996].

MarazzInI, Claudio, 1998: La lingua italiana: profilo storico, Bolonya: || Mulino.

MigliorinI, Bruno, 1960: Storia della lingua italiana, Florència: Sansoni.
PISTOLESI, Elena, 2009: «Tradizione e traduzione nel corpus lulliano», Studia Lulliana, 49, 3-50.

SANTAGATA, Marco, 2011: «Introduzione» a Dante Alighieri, Opere, dir. Marco Santagata. Vol. I: Rime, Vita Nova, De vulgari eloquentia, ed. Claudio Giunta Guglielmo Gorni i Mirko Tavoni. Milà: Mondadori, XI-CXXXII.

TAvonI, Mirko, 1996: «ll nome di poeta in Dante», Studi offerti a Luigi Blasucc dai colleghi e dagli allievi pisani, ed. L. Lugnani et al., Pisa: Pacini, 545-77. 